\title{
The effect of post-weld heat-treatment (PWHT) and vibratory assisted welding (VAW) on hardness of 304L stainless steels material
}

\author{
Muvvala Chinnam Naidu ${ }^{* *}$ and K T Balaram Padal ${ }^{2}$ \\ Reasearch Scholar, Department of Mechanical Engineering, Andhra University College of Engineering, Andhra \\ University, Visakhapatnam, Andhra Pradesh, India ${ }^{1}$ \\ Professor, Department of Mechanical Engineering, Andhra University College of Engineering, Andhra University, \\ Visakhapatnam, Andhra Pradesh, India ${ }^{2}$
}

Received: 19-July-2021; Revised: 17-November-2021; Accepted: 19-November-2021

(C)2021 Muvvala Chinnam Naidu and K T Balaram Padal. This is an open access article distributed under the Creative Commons Attribution (CC BY) License, which permits unrestricted use, distribution, and reproduction in any medium, provided the original work is properly cited.

\begin{abstract}
Welding is the most common and frequently used method to join the components. The fusion welding process is the one that is a commonly used method to join $304 \mathrm{~L}$ stainless steel materials. The fusion welding process generates much residual stresses within the materials. Residual stresses can be modified by a few techniques like preheating post-weld heat treatment but it takes more time and requires specific tools. Vibratory assisted welding is introduced to reduce welding defects. In this, a comparative study has been carried between post-weld heat treatment and vibratory assisted welding for the hardness of $304 \mathrm{~L}$ stainless steel. From the test results, Post-Weld Heat-Treatment (PWHT) and vibratory assisted welding are two effective methods to increase the hardness of the weldments. $13 \%$ and $18 \%$ improvement in the hardness of $304 \mathrm{~L}$ stainless is observed in the case of PWHT and vibratory assisted welding, respectively, to the conventional welding. Even though both PWHT and Vibratory Assisted Welding (VAW) as exhibiting almost similar results PWHT processes are more time-consuming, costly, and Laborious. From the current research, it is identified Vibratory assisted welding is the best suitable technique for reducing weld defects and enhancing properties.
\end{abstract}

\section{Keywords}

Heat treatment, Vibration welding, Hardness, Stainless steel, Frequency.

\section{Introduction}

Welding is widely used in most fabrication domains, and it is especially important in engineering fields like shipbuilding, structural structures, automotive, and aerospace [1]. Compared to bolted or riveted joints, welding allows for a less-weight joint. Welding provides a permanent joint but it affects the metallurgy of the components. During the joining process through welding, due to the extreme input of heat, the regions near the weld experience severe thermal cycles, thus producing plastic deformation homogeneously at the weld region. This, in turn, induces residual stresses. Due to the residual stresses, the service life of the weld joint is reduced. Grain size and microstructure have a significant impact on the mechanical properties of weldments. Finegrained materials have superior ductility and strength compared to coarse-grained ones [2,3].

*Author for correspondence

1514
To overcome this , different methods are used i.e., weld sequence, preheating, design considerations, natural aging, heat-treatment after welding, vibratory stress relief Weld pool oscillation, welding torch vibrations, and work piece vibrations are some mechanisms used to generate fine-grained structure[4-6].

One of the age old methods is Post Weld Heat Treatment (PWHT) process. It is used on a regular basis to ensure that the material strength of a part is retained after welding. PWHT can be used to minimize residual stresses, hardness control, and even improve material strength. PWHT includes a wide range of potential treatments, the most common of which are post-heating and stress relief. This PWHT process mainly encompasses heating the welded material to a definite temperature and cools the material gradually.

If PWHT is done incorrectly or not done at all, residual stresses can combine with load stresses to 
exceed a material's design limitations. This can result in weld failures, increased cracking potential, and increased brittle fracture susceptibility. And another disadvantage is that, process is laborious, time consuming and skilled technician observation is very much needed.

To replace these PWHT processes a novel technique is introduced that is Vibratory Assisted Welding (VAW). It is the process of imparting vibrations to the workpiece in regular intervals of time with force. During the process of welding, to enhance the welded joints mechanical properties and to replace the PWHT process, vibratory assisted welding is the best suitable technique. Studies reveal that the effect of vibrations reduces the welding residual stresses. Few researchers focused on the effect of vibrations on the mechanical properties of welded joints [7]. Effect of harmonic vibrations on the distribution and size of intermetallic compounds during MIG welding of AA5083-H321 aluminum joints were studied. Authors observed that Intermetallic compounds were increased to $7 \%, 13 \%$, and $26 \%$ for the specimen welded with a vibratory force of $400 \mathrm{~N}, 2200 \mathrm{~N}$, and $3150 \mathrm{~N}$, when compared with the specimens, welded without any vibrating force of welded joint [8]. Finally the weld defects can minimize with PWHT process and these PWHT processes are completely replaced with VAW. But the comparison of weld joints hardness property between the conventional welding, PWHT process and vibratory assisted welding is not done. In this paper the comparison is made in between the above process and results were discussed.

\section{Literature review}

2.1The effect of Vibratory assisted welding (VAW) Welding residual stresses are the key factors for reducing service or fatigue life. The vibratory stress relief method is the one that can reduce the welding residual stresses predominantly. The vibratory stress relief method can be simulated using the finite element method to find the welding residual stresses. The results obtained by FEM compared with the Hole drilling method using strain gauges to measure the welding residual stresses. There is a significant reduction in the welding residual stresses using vibratory stress relief [9]. Similarly Thermomechanical examination is carried to evaluate the distribution of thermal and residual stresses through numerical simulation $[10,11]$.

Two different vibration setups i.e., Local Vibration Effect (LVE) and Global Vibration Effect (GVE), and the effect of these vibration setups on the mechanical properties and microstructural behaviour was investigated. Authors found that GVE has a significant effect on the microstructure and mechanical properties compared to LVE [12].

Vibratory welding has a positive effect on the mechanical properties of aluminium welded connections. The authors studied the effect of time of vibration and vibration voltage on the ultimate tensile strength of the aluminum welded connections. The authors observed that vibratory welding voltage has a significant effect on the ultimate tensile strength and hardness $[13,14]$. Mechanical excitations to the vibrating table and electrode also have a significant effect on the mechanical properties of 1018 mild steel. The authors observed that stirring of weld pool with the mechanical excitations influences the hardness and ultimate tensile strength of the 1018 mild steel properties along with the grain structure [15-17].

A novel vibratory welding setup was capable of inducing vibrations at the natural frequency. The authors analysed the influence of vibration frequency, welding speed and welding current on the mechanical properties of mild steel-welded specimens. The optimization technique like surface roughness method has been used to understand the most influential factor for the weld joint strength [18].

\subsection{Effect of post weld heat treatment (PWHT)}

Effect of vibrations and thermal stress relief on the reduction of residual stresses was investigated. Using the finite element method, a simulation has been conducted on steel stiffeners. Different amplitudes and frequencies (sub-resonant) of vibrations have been applied on steel stiffener and residual stresses were monitored [19].

PWHT is a type of heat treatment that is done to welded joints after the welding process is completed to progress mechanical qualities and prevents brittle fracture by altering the metal-metallurgical structure. On the other hand, necessitates the use of specialized instruments and takes longer to finish. To improve the characteristics of welded joints, some researchers have used the PWHT method, which included solution behavior for $30 \mathrm{~min}$ at $5350 \mathrm{C}$, trailed by water-quenching and artificial aging for $12 \mathrm{hrs}$ at 1750C. PWHT is used on flexible polarity gas weldedAA2219 aluminum alloy joints in this study [20]. Ahmed et al explored PWHT was used at very high temperatures for 0.5 to $50 \mathrm{hrs}$ with 0.5 -time 
interval to progress the tensile \& impact-strength of weld-zone [21]. PWHT was applied to Cr-Mo Steel with Shielded Metal Arc Welding (SMAW) in this study, the shaking in engine oil reports less strength compared with PWHT neem-oil quenching is reports improved tensile \& hardness of weld-joints. Compared to quenching in neem oil, PWHT with quenching in engine oil improved impact strength. In GMAW, joint strength is enhanced for duplex stainless steel [22]. PWHT is used to improve the tensile \& hardness of an AA6661 welded-junction when it is related to weld-joint. The hardness \& tensile of the PWHT-joint is increased by $25.6 \%$. Improvement in the mechanical properties of the weld-zone was due to fine-grain structure and a minor gap among grains, which SEM photos captured [23].

The hardness \& tensile properties of SM steel was studied with aging at $4600 \mathrm{C}$ and superior results were attained [24]. PWHT considerably enhanced the tensile property of aluminum AA2219 alloy. PWHT was conceded at 5350C for half an hour, trailed by water-quenching and artificial aging at $1750 \mathrm{C}$ for 12 h. At the weld junction, a more homogeneous microstructure was formed [25]. Impact toughness of an SMA weld-joint of a pressure-vessel is processed with PWHT after $40 \mathrm{~h}$ of welding at 6200C. Hardness and transverse weld strength, on the other hand, are reduced. The softening of the weld joint in PWHT is responsible for the increased impact toughness [26].

Aging temperatures below 11500C, significantly improves the micro-level hardness of the TIG-weld duplex steel. PWHT was administered to the joints for $60 \mathrm{~min}$ at temperatures ranging from 80011500C. The weld-joints tensile, impact $\&$ hardness of high-strengthened steel with PWHT at $6000 \mathrm{C}$ for 1 to $3 \mathrm{~h}$ with an interval of $1 \mathrm{hr}$ were all enhanced [27, 28].

From the literature, welding residual stresses were measured by the hole drilling method using strain gauges. Local and global vibration has a significant influence on the microstructure and mechanical properties of welded joints. Welding simulations have been conducted on steel stiffeners and applied sub-resonant frequencies and observed that there is a significant reduction in the residual stresses.

Most of the researchers focused on the reduction of residual stresses. Residual stresses in the welded joints arise due to uneven heat input and cooling cycles. The main objective of this paper is to understand the behavior of the heat treatment after welding and welding with vibrations on the hardness of 304L stainless steel. Here in the case of vibrations during welding, along with the above-mentioned objectives, an attempt is made to analyze the heat input and vibrations on the hardness. In the case of heat treatment after welding, the effect of various heat input ranges on the hardness of $304 \mathrm{~L}$ stainless steel specimens.

\section{Experimental methodology}

3.1PWHT process

In this study, arc welding was performed for SS 304L steels to know the hardness. The material compositions are represented in Table 1. A plate of $20 \mathrm{~mm}$ width, $200 \mathrm{~mm}$ length, and $5 \mathrm{~mm}$ thickness is considered and joined using SMAW process. To analyze the hardness of SS 304L weldments, PostWeld Heat-Treatment was implemented at $650^{\circ} \mathrm{C}$ to $1050^{\circ} \mathrm{C}$ at an interval of $200^{\circ} \mathrm{C}$ which is shown in Figure 1. The range of temperatures maintained is $1 \mathrm{hr}$ to $4 \mathrm{hr}$, with an interval of $1 \mathrm{hr}$. In every stage, the prepared specimens are quenched in cold water for analysing the hardness of the material at temperatures and at different time intervals.

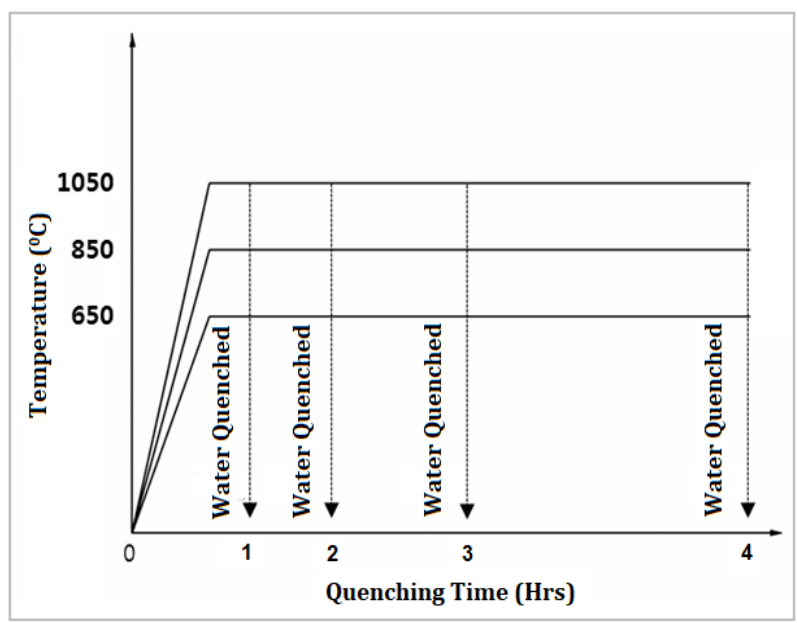

Figure 1 Heat treatment at different temperatures and quenching time

\subsection{Vibratory assisted welding}

Four springs along each corner were fitted with a platform for placing the specimen. By adding a vibromotor to the vibratory table setup, the vibration platform was prepared. To produce the vibrations, an ammeter, voltmeter, and a dimmerstat were connected to the vibromotor. The experimental setup is shown in Figure 2. A supplementary vibratory setup that is proficient in producing mechanical 
excitations to the weld-pool for "manual metal arc welding" is developed to improve the weldment mechanical properties by imparting constructive alterations in the microstructure of the weld region.
Different frequencies were imparted along the weldbead length at various amplitudes, only trailing behind the welding arc to mechanically stir the weld pool to induce desirable microstructural results.

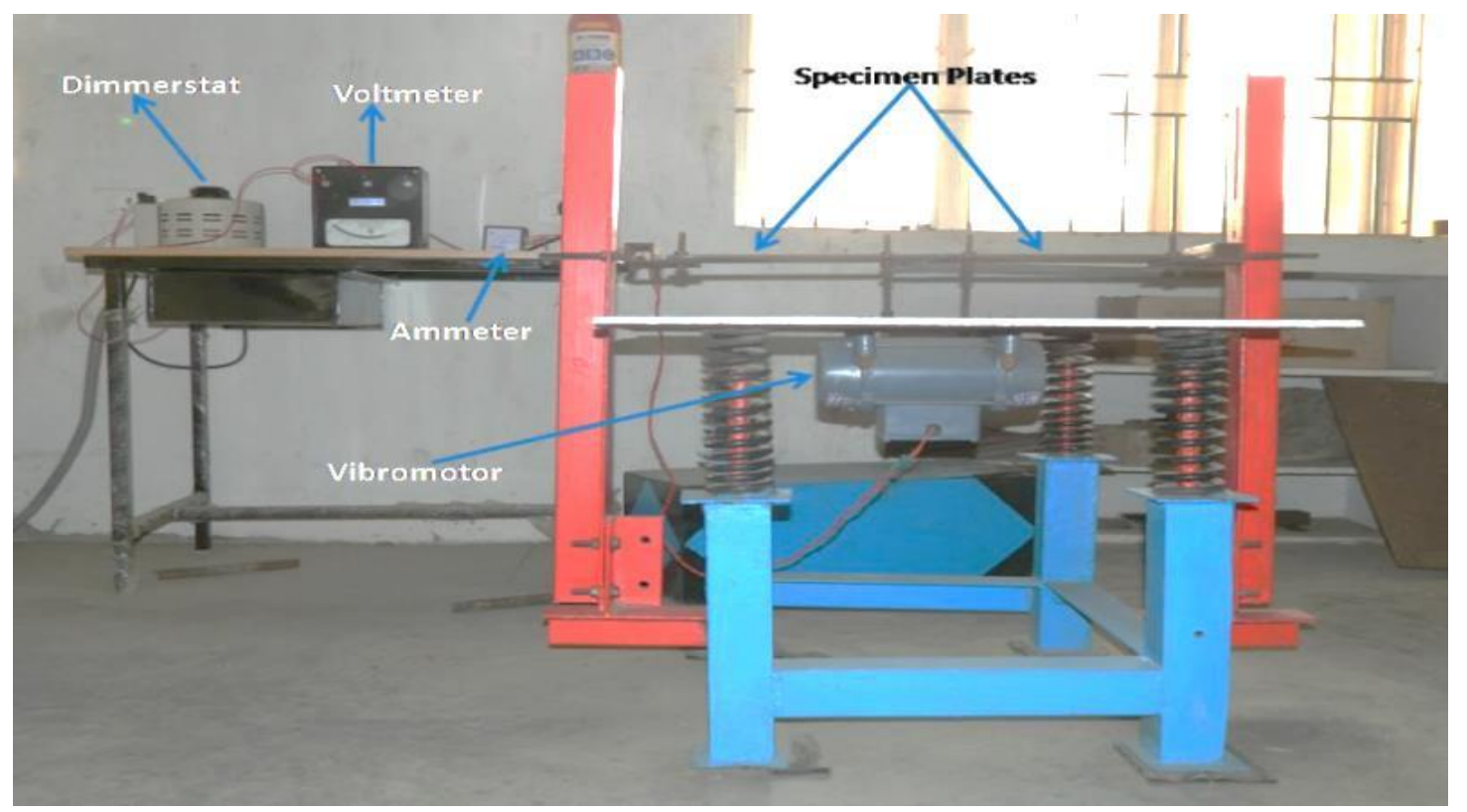

Figure 2 Experimental setup

In terms of voltages, this setup generates the appropriate frequency with amplitude. Table 1 lists the differences in acceleration and amplitude at 70 , 150 , and $230 \mathrm{~V}$ voltages. Figures 3 and 4 display the difference in acceleration and amplitude to the input voltage. Beneath the low heat inputs (90-110 A) was the prepared butt-welded joints. To fill the void, there are two passes, the first is the main pass and the second are the root pass. Vibrations transferred to the molten pool up to the solidification state of the weld bead.

\subsection{Materials and the weld-joint preparation}

In this present examination, 304L stainless steel material of thickness $5 \mathrm{~mm}$ is selected as the base material. Its material composition is in (\% weight) carbon.(C) - 0.3\%, Manganese.(Mn) - $2 \%$, Phosphorus.(P) $-0.045 \%$ and sulfur.(S) $-0.03 \%$, Silicon.(Si) - 0.75\%, Nickel.(Ni) $-8 \%$ and Nitrogen. $(\mathrm{N})-0.1 \%$ which is shown in Table 1 . As per standard, the weld joints were prepared by inducing mechanical excitations to hardness property to examine the characteristics of vibrations. Excellent formability, high strength and good corrosion resistance makes 304L Stainless steel material is used for several applications in manufacturing. Typical uses of 304L SS material include kitchen equipment, trim and architectural mouldings. And it is used in the paper, textile, chemical and pharmaceutical industries as processing equipment. For the preparation of the weld joints, specimens were fixed over the flat surface of the vibration table setup and Manual arc welding process is carried. While welding, the required number of vibrations was transferred to the specimens by alternating the dimmer-stat and voltmeter. Figure 3 shows the line diagram of specimen preparation before welding. The vibrations were transferred to molten pool during welding continuously throughout the process.

The vibrations were measured using a specific device called vibro-meter. Here the velocity, acceleration and displacement are measured for every setoff vibration.

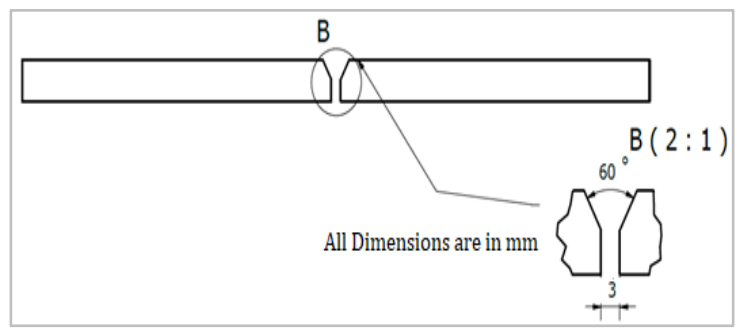

Figure 3 Weld joint dimensions 
Muvvala Chinnam Naidu and K T Balaram Padal

Table 1 SS 304L chemical composition

\begin{tabular}{lllllllll}
\hline & \multicolumn{7}{c}{ Chemical composition (Wt\%) } \\
\cline { 2 - 10 } Stainless steel material Grade & $\mathrm{C}$ & $\mathrm{Si}$ & $\mathrm{Mn}$ & $\mathrm{P}$ & $\mathrm{S}$ & $\mathrm{Cr}$ & $\mathrm{Ni}$ & $\mathrm{N}$ \\
\hline 304L & 0.03 & 0.75 & 2 & 0.045 & 0.03 & 18 & 8 & 0.1 \\
\hline
\end{tabular}

3.4Hardness test of weldments

The "Rockwell Hardness Test" is considered for hardness characterization on weld joints. The weldjoints are indented with the spherical-shaped indenter, at several load conditions. The hardness values vary with the varying load, the amount of load considered during the hardness calculation must therefore be specified. From references, the current protocols and guidelines can be accessed. RHN (Rockwell Hardness Number) values for the weldments within $10 \mathrm{kgf}$ of minor-load and $150 \mathrm{kgf}$ of major-load, are measured. The general hardness formula for measuring the RHN value is given in Equation 1.

$\mathrm{RHN}=(\mathrm{N}-(\mathrm{d} / \mathrm{s}))$

Where:

$\mathrm{N}$ and $\mathrm{S}$ - Scale factors;

$\mathrm{D}$ - Depth of indentation.

The weld joints maximum RHN values are noted at $150 \mathrm{kgf}$ load.

\section{Experimental results and discussions}

Figure 4 illustrates the hardness test procedure under various load conditions on a "Rockwell hardness testing" unit. Here the hardness values of weld-joints were measured along the weld-bead and Fusion zone for the samples processed with PWHT and VAW. Hardness values are considered at a distance of $10 \mathrm{~mm}$ gap for each measurement along with the weld bead in the experiment.

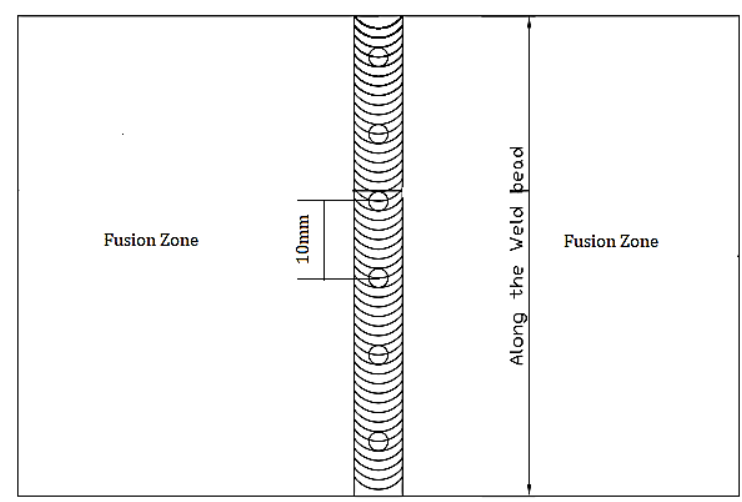

Figure 4 Weld Joint Zones

\subsection{Heat treated specimens}

Initially, the specimens are prepared without any implication of vibrations and those specimens were transferred to the Post-Weld Heat-Treatment process. 1518
The process is carried at a temperature of $650^{\circ} \mathrm{C}$ to $1050^{\circ} \mathrm{C}$ at an interval of $200^{\circ} \mathrm{C}$ and the time is taken for heat treatment is $1 \mathrm{Hr}$ to $4 \mathrm{Hrs}$ at an interval of $1 \mathrm{Hr}$. From the hardness results, it is identified that the weld specimen's heat treatment at $1050^{\circ} \mathrm{C}$ shows better results when it is compared with the heattreated at $650^{\circ} \mathrm{C}$ and $850^{\circ} \mathrm{C}$. The Figure 5 shows the hardness values of $304 \mathrm{~L}$ stainless steel at 1050 degrees centigrade. Hardness has been measured across the weld bead as the centre is considered base.

The graphs shown in Figure 5 represent that the hardness values are measured for the weld specimens which are undergone heat treatment process. During the experimentation specimens were heat treated at $650^{\circ} \mathrm{C}$ and $1 \mathrm{Hr}$ to $4 \mathrm{Hr}$ at an interval of $1 \mathrm{Hr}, 850^{\circ} \mathrm{C}$ and $1 \mathrm{Hr}$ to $4 \mathrm{Hr}$ at an interval of $1 \mathrm{Hr}$ and $1050^{\circ} \mathrm{C}$ and $1 \mathrm{Hr}$ to $4 \mathrm{Hr}$ at an interval of $1 \mathrm{Hr}$. By observing the results at different temperatures and time, it is concluded that at $1050{ }^{0} \mathrm{C}$ the material hardness property is more compared with the other temperatures. In Figure 5 Hardness values of PWHT at (a) $1050^{\circ} \mathrm{C}, 1 \mathrm{Hr}$ (b) $1050^{\circ} \mathrm{C}, 2 \mathrm{Hr}$ (c) $1050^{\circ} \mathrm{C}, 3 \mathrm{Hr}$ (d) $1050^{\circ} \mathrm{C}, 4 \mathrm{Hr}$ are taken along the Fusion zone and along the heat-affected zone. The peak hardness value is obtained at $1050^{\circ} \mathrm{C}$, $4 \mathrm{hrs}$ that is $82 \mathrm{RHN}$ when it is compared with the less time intervals. During the heat treatment process, the heat affected zone of 304L Stainless steel has less thermaldiffusivity than the other metals. Due to the material grade is transformed from austenitic stainless steel to martensitic that allows the HAZ of metal as weaker.

4.2Vibratory assisted welding specimens

During the welding process the specimens were welded with vibrations by varying vibration voltage and welding current. Here, the voltage of the vibromotor is varied from $60 \mathrm{~V}$ to $230 \mathrm{~V}$ with an interval of $10 \mathrm{~V}$ and the welding current is varied from 90amps to 130amps with an interval of $20 \mathrm{amps}$. Initially at $0 \mathrm{~V}$ voltage (without any vibrations, conventionally welded), the specimens are welded and gradually the voltage is increased (With vibrations) during the welding process.

The specimens are welded with vibro-motor voltage ranges from $60 \mathrm{~V}$ to $230 \mathrm{~V}$ with an interval of $20 \mathrm{~V}$ at 90amps, $60 \mathrm{~V}$ to $230 \mathrm{~V}$ with an interval of $20 \mathrm{~V}$ at 
$110 \mathrm{amps}$ and $60 \mathrm{~V}$ to $230 \mathrm{~V}$ with an interval of $20 \mathrm{~V}$ at $130 \mathrm{amps}$. Initially, the hardness of the specimens is low and gradually increases with the increase of vibrations for 90amps, 110amps, and 130amps from $60 \mathrm{~V}$ to $180 \mathrm{~V}$ and again it is dropped from $180 \mathrm{~V}$ to $230 \mathrm{~V}$.

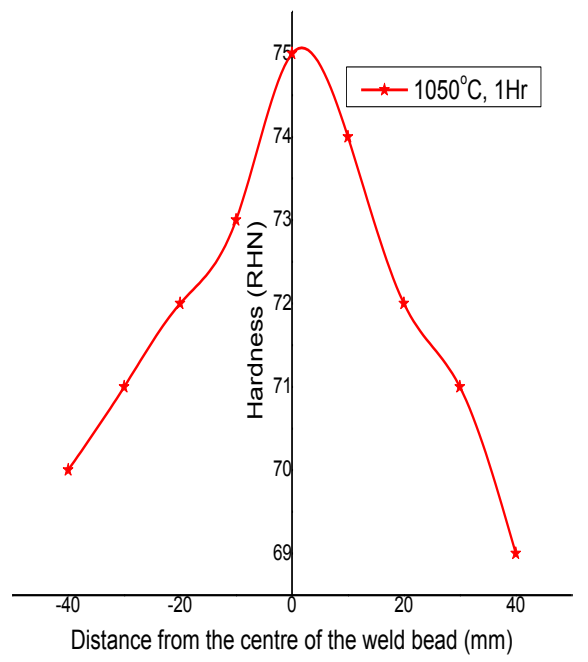

(a)

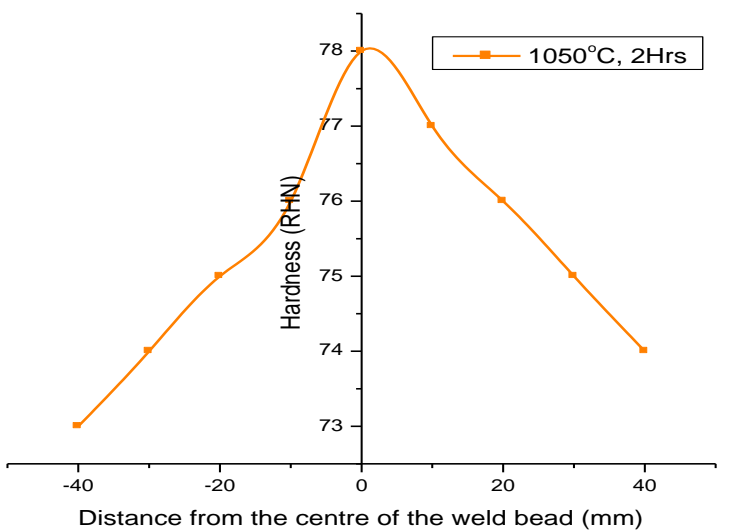

(b)

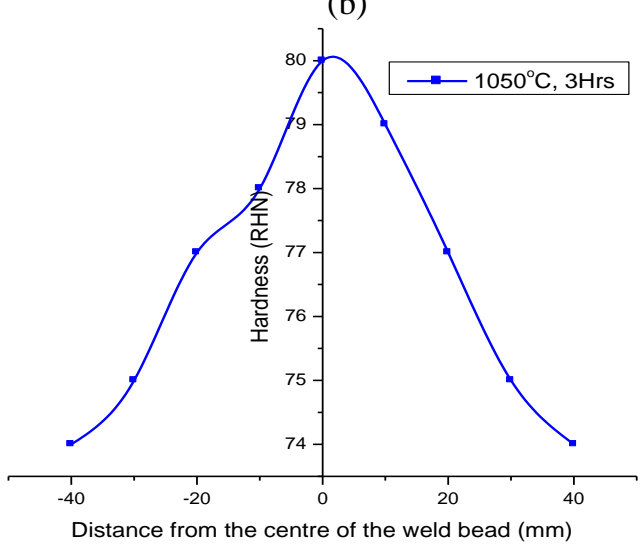

(c)

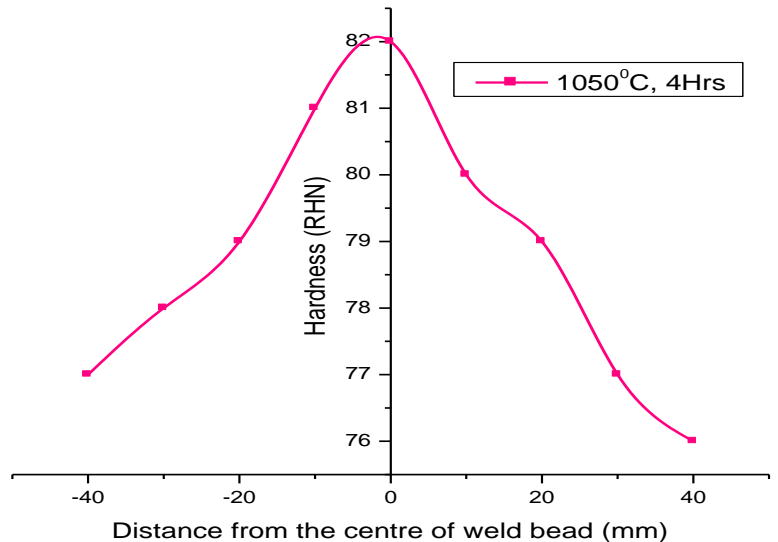

(d)

Figure 5 Hardness values of PWHT at (a) 10500C, $1 \mathrm{Hr}$ (b) $10500 \mathrm{C}, 2 \mathrm{Hrs} \mathrm{(c)} 10500 \mathrm{C}, 3 \mathrm{Hrs}$ (d) $10500 \mathrm{C}$, $4 \mathrm{Hrs}$.

The peak value of hardness is identified at $180 \mathrm{~V}$ of vibromotor and 110 amps of welding current for 90amps, 110amps and 130amps due to the material grade is transformed from austenitic stainless steel to martensitic that allows the HAZ of metal as weaker those results are shown in Figure 6.

The improved hardness with the increased vibrations is due to fine grain refinement of weld-pool during the welding process with excitations. After $180 \mathrm{~V}$ of vibromotor voltage, the hardness value is gradually drops because of increased arc gap with high frequency vibrations.

From the above Figure 6, it is identified that the peak values of hardness is obtained at $180 \mathrm{~V}$ with different welding currents that is $90 \mathrm{amps}, 110 \mathrm{amps}$ and 130 amps. By considering these input parameters the specimens were tested for the hardness along the weld-bead at a gap of $10 \mathrm{~mm}$ for each measurement.

The graphs shown in Figure 7 represent that the hardness values are measured for the weld specimens are prepared with and without vibrations. During the experiments, specimens which are welded at $180 \mathrm{~V}$ of vibro-motor and welding currents of 90amp, $110 \mathrm{amp}$, and 130amp showing the peak values of hardness. During this process the specimens are also prepared conventionally of welding those results also shown in Figure 7 (a). When compared the results of conventional welding with vibrations welding the hardness values are increased due to the refinement of weld-pool during the welding process. And the maximum values of the hardness obtained at the weld bead and gradually reduced at heat-affected zone. 
Here also with vibration parameter the welding current also influences the hardness property of weldment. From Figure $7(b)$ the specimens are prepared at $180 \mathrm{~V}$ of vibro-motor and $90 \mathrm{amps}$ of welding current the hardness maximum value is obtained as $76 \mathrm{RHN}$, at $180 \mathrm{~V}$ of vibro-motor and 110 amps of welding current the hardness maximum value is obtained as $85 \mathrm{RHN}$ and at $180 \mathrm{~V}$ of vibromotor and 130 amps of welding current the hardness

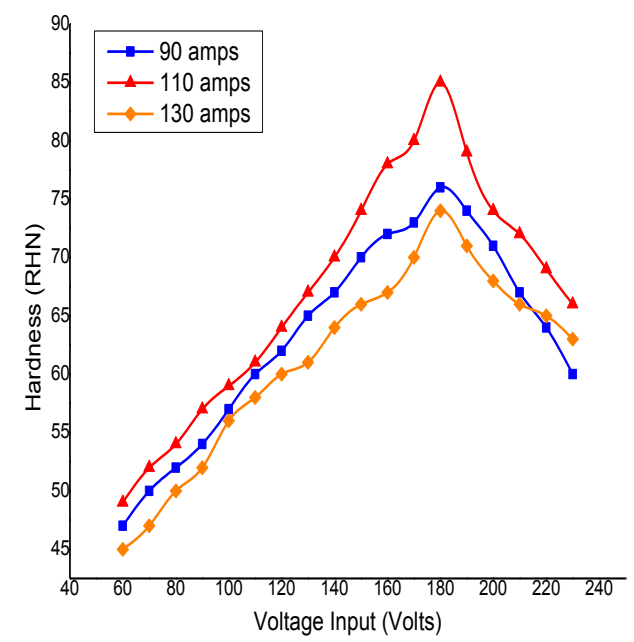

Figure 6 Comparison of Hardness of SS 304L at different vibromotor voltage and welding current

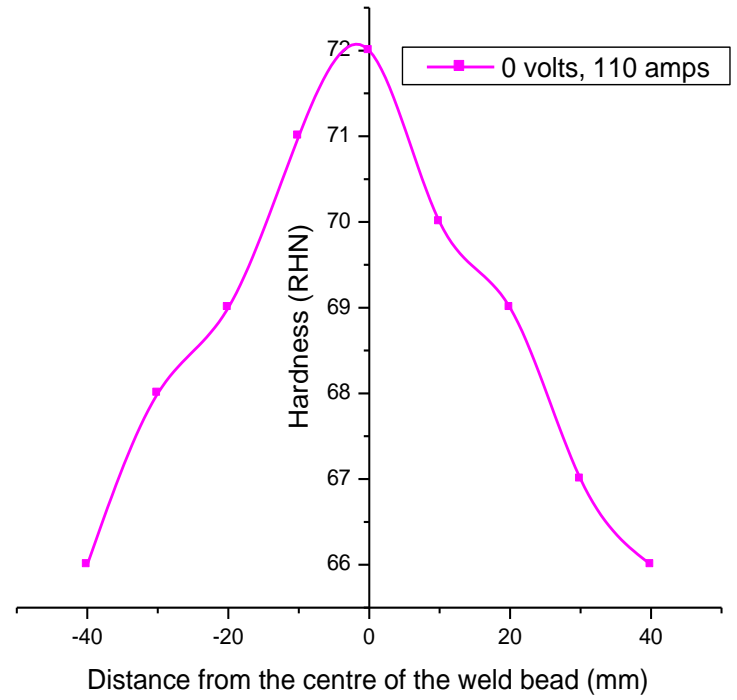

(a) maximum value is obtained as 74 RHN. So by observing the results maximum value of hardness is obtained at $180 \mathrm{~V}$ and 110amps. Due to molten pool excitation during welding the large dendrites are breaks down in to small dendrites and the grain size also decreasing with vibration. Because of the grain size reduction with vibrations the hardness values are increased for SS 304 L materials.

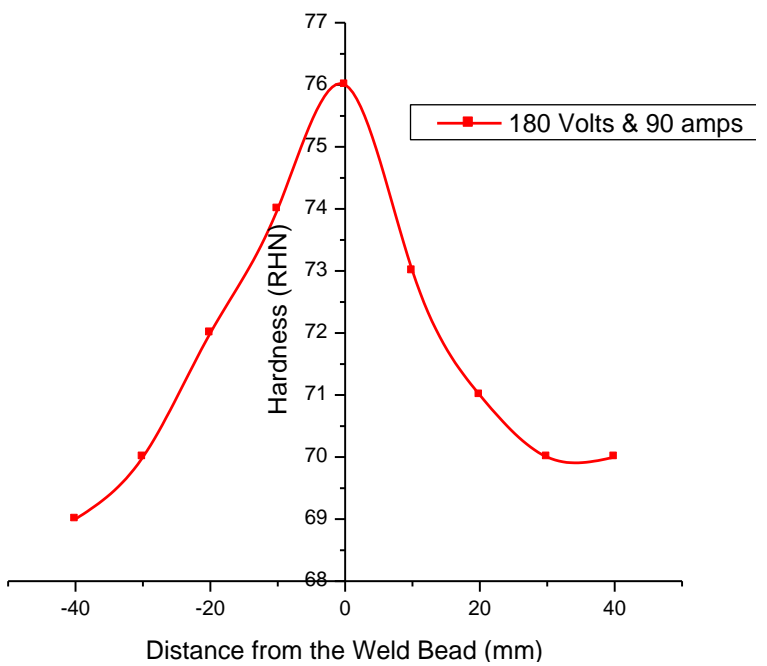

(b)

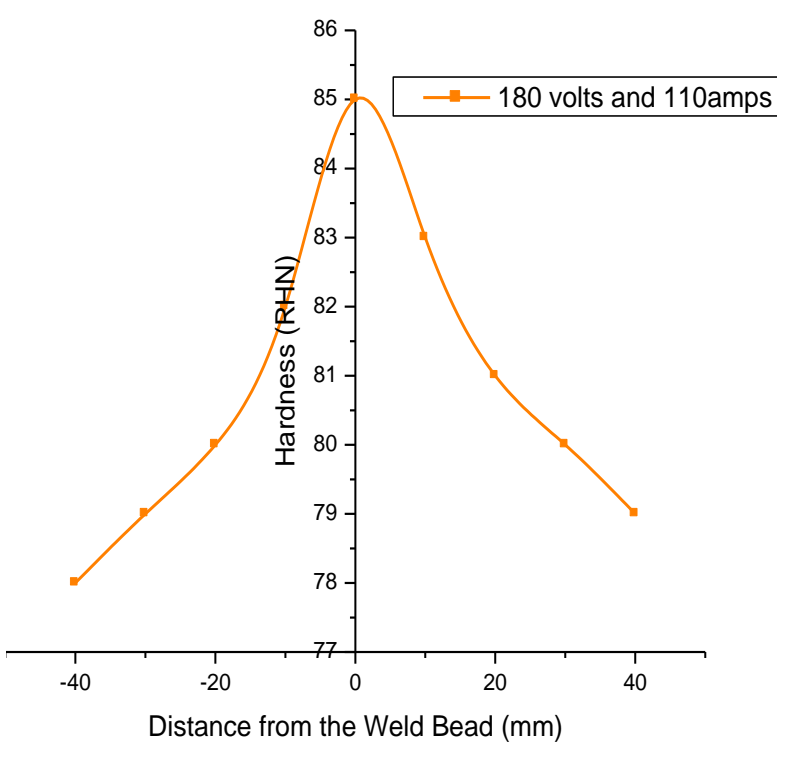

(c) 


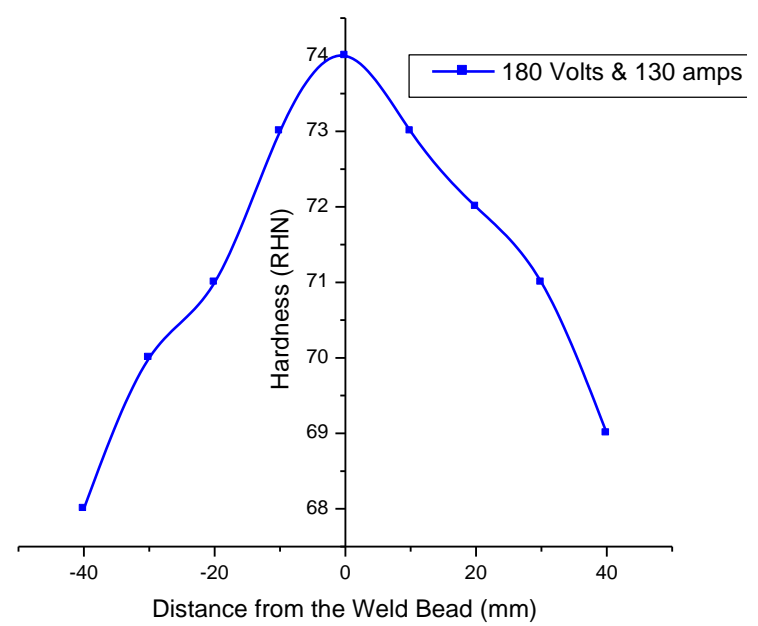

(d)

Figure 7 Hardness values of vibratory assisted weld joints at (a) $0 \mathrm{~V} \& 110 \mathrm{amps}$ (b) 180 \& 90amps (c) $180 \& 110 \mathrm{amps}$ (d) $180 \& 130 \mathrm{amps}$

4.3Comparison of heat treated weld joints and vibratory assisted weld joints

The hardness values of the conventional welded specimens, heat-treated specimens and vibratory assisted specimens are compared with each other and identified that the results of vibratory assisted welding are slightly more than the heat-treated specimens, which are as shown in Figure 8 at optimum working conditions. The maximum hardness obtained for the joints undergone for heat treatment is $82 \mathrm{RHN}$ at $1050^{\circ} \mathrm{C}$ and $4 \mathrm{hrs}$. And the maximum hardness obtained for the joints prepared with vibrations is $85 \mathrm{RHN}$ at $180 \mathrm{~V}$ of vibro-motor and 110amps of welding current. But the hardness value of conventionally prepared weld joints is
72 RHN, which is less than the above two processes. Both PWHT and VAW are much suitable for reducing the residual stresses and other weld defects for improving the weld joint hardness.

In Figure 8, the hardness values of the weldments along with the weld bead and HAZ are compared for the weld joints prepared at 110 amps with conventional welding and welded joints with heat treatment that is at $1050^{\circ} \mathrm{C}$ and $4 \mathrm{Hrs}$ heat treatment with welded joints prepared under the influence of vibrations. From the results, it is confirmed that the hardness value for the conventional welding process is less compared with the PWHT and VAW because of weld defects. Due to the refined grain structure with PWHT and VAW, the hardness is increased. And compared with the PWHT and VAW process, Vibratory assisted welding exhibited slightly more hardness. This is because of the continuous refinement of grains with vibrations before attaining the solid-state. A complete list of abbreviations is shown in Appendix I.

\subsection{Limitations of vibratory assisted welding}

- Vibratory assisted welding is suitable for only molten state welding like "SMAW-Shielded metal arc welding, MIG-Gas Metal Arc Welding (GMAW) and TIG-Gas Tungsten Arc Welding (GTAW)."

- During welding process with vibrations if the amplitude is more than $0.5 \mathrm{~mm}$ leads to arc gap

- Maintaining constant frequency while welding is a challenge.

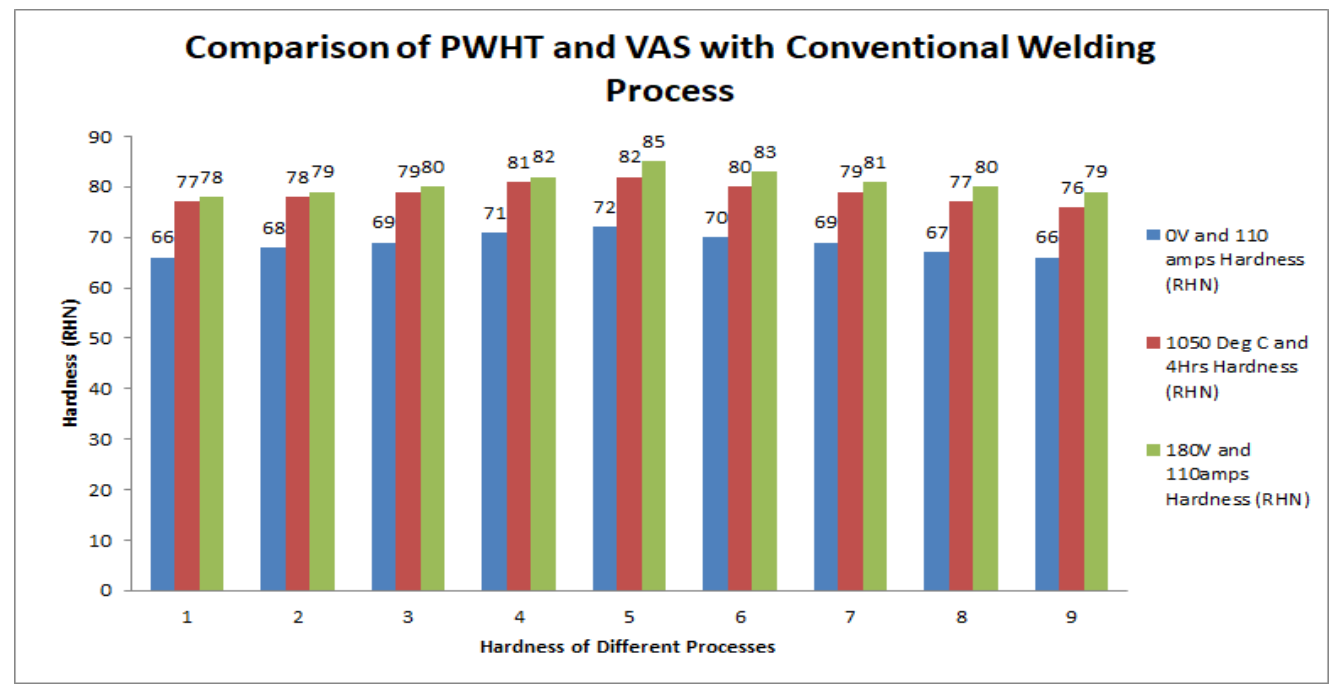

Figure 8 Comparison of PWHT and VAW with conventional welding process 


\section{Conclusion and future work}

The hardness of the 304L Stainless Steel is enhanced with PWHT and VAW Process when it is related to the conventional-welding process. The enhanced results are due to reduced weld defects and residual stresses by refining the grain structure with PWHT and VAW processes. Also, the comparison is made between PWHT and VAW and identified that Vibratory assisted welding exhibited slightly more hardness. Even though both PWHT and VAW as exhibiting similar results PWHT processes are more time-consuming, costly, and Laborious. From the current research, it is identified Vibratory assisted welding is the best suitable technique for reducing weld defects and enhancing properties. The following are the major outcomes from the current work

- The hardness of 304L stainless steel enhanced with the vibratory assisted welding and post-weld heat treatment process compared with the conventional welding process.

- With the post-weld heat treatment percentage increase in the hardness of $304 \mathrm{~L}$ stainless steel is $13 \%$ compared to conventional welding

- The percentage increase in the hardness of $304 \mathrm{~L}$ stainless steel is $18 \%$ in the vibratory assisted welding method compared to the conventional welding process.

- Hardness of 304L stainless steel has greatly influenced by the vibratory assisted welding than the post-weld heat treatment process

Mechanical properties like flexural, tensile, fatigue and impact can be investigated further. The microstructure of the weld-zone can also be investigated and analyzed by using this method.

\section{Acknowledgment}

None.

\section{Conflicts of interest}

The authors have no conflicts of interest to declare.

\section{References}

[1] Ghazvinloo HR, Honarbakhsh-raouf A, Shadfar N. Effect of arc voltage, welding current and welding speed on fatigue life, impact energy and bead penetration of AA6061 joints produced by robotic MIG welding. Indian Journal of Science and Technology. 2010; 3(2):156-62.

[2] Moarrefzadeh A. Finite-element simulation of aluminum temperature field and thermal profile in laser welding process. Indian Journal of Science and Technology. 2012; 5(8):3177-82.
[3] Jayapriya J, Muruganandam D, Thirusangu K, Das SL. Parametrical analysis of friction stir welding of dissimilar aluminum AA7075 and AA2024 using graph labeling. Indian Journal of Science and Technology. 2012; 5(8):3223-6.

[4] Kou S, Le Y. Nucleation mechanism and grain refining of weld metal. Welding Journal. 1986; 65(4):65-70.

[5] Tewari SP, Shanker A. Effects of longitudinal vibration on the mechanical properties of mild steel weldments. Proceedings of the Institution of Mechanical Engineers, Part B: Journal of Engineering Manufacture. 1993; 207(3):173-7.

[6] Qinghua L, Ligong C, Chunzhen N. Effect of vibratory weld conditioning on welded valve properties. Mechanics of Materials. 2008; 40(7):56574.

[7] Munsi AS, Waddell AJ, Walker CA. Vibratory weld conditioning: treatment of specimens during cooling. Proceedings of the Institution of Mechanical Engineers, Part L: Journal of Materials: Design and Applications. 2000; 214(3):129-38.

[8] Tamasgavabari R, Ebrahimi AR, Abbasi SM, Yazdipour AR. Effect of harmonic vibration during gas metal arc welding of AA-5083 aluminum alloy on the formation and distribution of intermetallic compounds. Journal of Manufacturing Processes. 2020; 49:413-22.

[9] Ebrahimi SM, Farahani M, Akbari D. The influences of the cyclic force magnitude and frequency on the effectiveness of the vibratory stress relief process on a butt welded connection. The International Journal of Advanced Manufacturing Technology. 2019; 102(5):2147-58.

[10] Vemanaboina H, Gundabattini E, Kumar K, Ferro P, Sridhar BB. Thermal and residual stress distributions in inconel 625 butt-welded plates: simulation and experimental validation. Advances in Materials Science and Engineering. 2021.

[11] Nagel L, Herwig A, Schmidt C, Horst P. Numerical investigation of residual stresses in welded thermoplastic CFRP structures. Journal of Composites Science. 2021; 5(2):1-10.

[12] Ingram E, Golan O, Haj-ali R, Eliaz N. The effect of localized vibration during welding on the microstructure and mechanical behavior of steel welds. Materials. 2019; 12(16):1-17.

[13] Rao MV, Babu BS. Vibratory weld conditioning during gas tungsten arc welding of al 5052 alloy on the mechanical and micro-structural behavior. World Journal of Engineering. 2020; 17(6):831-6.

[14] Vykuntarao M, Rao PS, Babu BS. Effect of transverse vibrations on the hardness of aluminum 5052 H32 alloy weldments. International Journal of Mechanical Engineering and Technology. 2019; 10(1):327-33.

[15] Bade VS. The effect of vibratory conditioning on tensile strength and microstructure of 1018 mild steel. World Journal of Engineering. 2020; 17(6):837-44.

[16] Bade VS. Experimental investigation on influence of electrode vibrations on hardness and microstructure of 
1018 mild steel weldments. World Journal of Engineering. 2020; 17(4):509-17.

[17] Suresh BV, Rao PS, Rao PG. Improvement of tensile strength of 1018 mild steel welded joints produced under the influence of electrode vibration. International Journal of Innovative Technology and Exploring Engineering. 2019; 8(8):1219-22.

[18] Singh PK, Kumar SD, Patel D, Prasad SB. Optimization of vibratory welding process parameters using response surface methodology. Journal of Mechanical Science and Technology. 2017; 31(5):2487-95.

[19] Pradhan R, Sunny MR, Sarkar A. Numerical study on weld residual stress reduction of a stiffened steel plate using vibration. Trends in the Analysis and Design of Marine Structures. 2019: 433-8.

[20] Ding JK, Wang DP, Ying WA, Hui DU. Effect of post weld heat treatment on properties of variable polarity TIG welded AA2219 aluminium alloy joints. Transactions of Nonferrous Metals Society of China. 2014; 24(5):1307-16.

[21] Ahmed SR, Agarwal LA, Daniel BS. Effect of different post weld heat treatments on the mechanical properties of Cr-Mo boiler steel welded with SMAW process. Materials Today: Proceedings. 2015; 2(45):1059-66.

[22] Tanimu I, Danjuma SY, Shekarau YA. Effects of gas metal arc welding techniques on the mechanical properties of duplex stainless steel. Journal of Minerals and Materials Characterization and Engineering. 2013.222-30.

[23] Ahmad R, Bakar MA. Effect of a post-weld heat treatment on the mechanical and microstructure properties of AA6061 joints welded by the gas metal arc welding cold metal transfer method. Materials \& Design. 2011; 32(10):5120-6.

[24] An J, Meng F, Lv X, Liu H, Gao X, Wang Y, et al. Improvement of mechanical properties of stainless maraging steel laser weldments by post-weld ageing treatments. Materials \& Design. 2012; 40:276-84.

[25] Zhu ZY, Deng CY, Wang Y, Yang ZW, Ding JK, Wang DP. Effect of post weld heat treatment on the microstructure and corrosion behavior of AA2219 aluminum alloy joints welded by variable polarity tungsten inert gas welding. Materials \& Design. 2015; 65:1075-82.

[26] Smith C, Pistorius PG, Wannenburg J. The effect of a long post weld heat treatment on the integrity of a welded joint in a pressure vessel steel. International Journal of Pressure Vessels and Piping. 1997; 70(3):183-95.

[27] Sharma C, Dwivedi DK, Kumar P. Effect of post weld heat treatments on microstructure and mechanical properties of friction stir welded joints of $\mathrm{Al}-\mathrm{Zn}-\mathrm{Mg}$ alloy AA7039. Materials \& Design. 2013; 43:134-43.

[28] Gomes AJ, Jorge JC, De SLF, Bott ID. Influence of chemical composition and post welding heat treatment on the microstructure and mechanical properties of high strength steel weld metals. Materials Science Forum. 2013; 758:21-32.

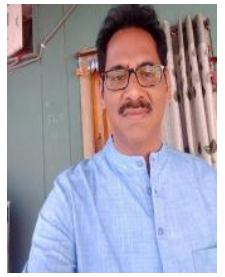

Muvvala Chinnam Naidu is an Ph.D. Scholar, Department of Mechanical Engineering, Andhra University College of Engineering. He has 17 years of teaching/research Experience. His areas of interest include Welding Technology and Manufacturing.

Email: chinnammuvvala@gmail.com

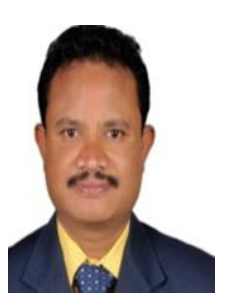

K T Balaram Padal is a Professor at Andhra University at Andhra University based in Visakhapatnam, Andhra Pradesh. He has 17 years of teaching/research Experience. He has been contributing its humble share of the Mechanical Engineering graduates for national needs. His areas of interest include Welding Technology and Manufacturing.

Email: ktbpadaldme@gmail.com

Appendix I

\begin{tabular}{lll}
\hline S. No. & Abbreviation & Description \\
\hline 1 & C & Carbon \\
\hline 2 & FEM & Finite Element Method \\
\hline 3 & GVE & Global Vibration Effect \\
\hline 4 & HAZ & Heat Affected Zone \\
\hline 5 & LVE & Local Vibration Effect \\
\hline 6 & MIG & Metal Inert Gas Welding \\
\hline 7 & Mn & Manganese \\
\hline 8 & N & Nitrogen \\
\hline 9 & Ni & Nickel \\
\hline 10 & P & Phosphorus \\
\hline 11 & PWHT & Post Weld Heat Treatment \\
\hline 12 & RHN & Rock Well Hardness Number \\
\hline 14 & S & Sulphur \\
\hline 15 & SEM & Scanning Electron Microscope \\
\hline 16 & SMAW & Silicon \\
\hline 17 & SS & Shielded Metal Arc Welding \\
\hline 18 & TIG & Stainless Steel \\
\hline 19 & VAW & Tungsten Inert Gas Welding \\
\hline
\end{tabular}

